\title{
Cooperação Internacional: desafios contemporâneos
}

\author{
International Cooperation: contemporary challenges
}

Cooperación Internacional: desafíos contemporáneos

Organizadores do dossiê:

Déborah Silva do Monte

Professora adjunta da Universidade da Grande Dourados (UFGD),

Dourados- MS, Brasil.

e-mail: deborahmonte@ufgd.edu.br

Orcid: https://orcid.org/0000-0002-4074-5715

Fátima Anastasia

Professora do Programa de Pós-Graduação Stricto Sensu em Relações Internacionais (PPGRI) da Pontifícia Universidade Católica de Minas Gerais (PUC Minas), Belo Horizonte- MG, Brasil. e-mail: fatima.anastasia@gmail.com Orcid: https://orcid.org/0000-0001-5839-9155

Pedro Andrade Matos

Professor da Universidade de Santiago, Ilha de Santiago, Cabo Verde e-mail: pedro.matos@us.edu.cv Orcid: https://orcid.org/0000-0003-1949-4138 
A cooperação é um fenômeno cada vez mais relevante nas Relações Internacionais. Novos estudos e análises sobre a ocorrência e as diferentes formas e tipos de cooperação têm contribuído para a compreensão de por que os atores estatais e não estatais cooperam, mesmo em um sistema internacional anárquico (AXELROD; KEOHANE, 1985). Uma das respostas a tal indagação se relaciona à capacidade de a cooperação gerar novos ganhos aos parceiros, dificilmente obtidos de maneira unilateral e sem grandes custos. E, também, de a evolução da cooperação (AXELROD, 2010) construir e/ou fortalecer reputações de atores orientados para a celebração de acordos críveis (LEEDS, 1999) e para a produção de benefícios compartilhados, ainda que, em geral, assimétricos.

Em um mundo cada vez mais interdependente, Estados e demais atores interessados não conseguem resolver problemas complexos de maneira isolada. Eles precisam da cooperação como ferramenta para garantir segurança mútua, regulamentar o trânsito crescente de bens, serviços, pessoas e ideias, bem como para desenvolver e compartilhar tecnologias direcionadas à solução de questões complexas que ameaçam a todos, sobretudo no atual contexto de enfrentamento da pandemia da COVID-19 e de mudanças climáticas (JAVED; CHATTU, 2020; ZARTMAN; TOUVAL, 2020; LEE, 2009).

A cooperação constitui uma das estratégias mais relevantes para enfrentar problemas e fenômenos que desconhecem fronteiras políticas e limites geográficos e que podem gerar consequências econômicas, sociais e políticas, nos níveis nacional, regional e internacional. Revela-se, portanto, como a segurança e o bem-estar de um ator internacional depende das ações e medidas adotadas por outros.

O momento atual é propício para forjar novos padrões cooperativos e que demandam dos atores a percepção de outros ganhos, além dos materiais. Seguindo as contribuições teóricas de Keohane (1988), a cooperação não ocorre em um ambiente harmônico, mas, sim, em um contexto de multiplicidade de interesses e de perspectivas, como se observa na atualidade. Nesse sentido, é fundamental fortalecer parcerias para a garantia dos direitos fundamentais, do desenvolvimento sustentável e da construção de um mundo menos desigual em termos sociais e econômicos (CHATURVEDI; SINGH, 2014; SATRUSTEGUI, 2013). 
Não se faz cooperação, todavia, apenas por meio de boas intenções e princípios. São necessários recursos financeiros, articulações entre os atores, normas, regras e valores compartilhados e muito engenho e arte para criar espaços de interação, possibilitar a partilha de tecnologias e o fortalecimento de instituições multilaterais, com vistas à distribuição dos ganhos cooperativos e à resolução dos problemas de ação coletiva.

O dossiê "Cooperação Internacional: desafios contemporâneos", publicado pela Monções: Revista de Relações Internacionais da Universidade Federal da Grande Dourados (UFGD), reúne treze trabalhos originais que examinam a cooperação em diferentes níveis de análise (internacional, regional, doméstico e subnacional) e mobilizam diferentes teorias e abordagens para investigar diversas dimensões (técnica, científica e tecnológica, econômica, financeira e política) e modalidades cooperativas (bilateral, trilateral e multilateral), envolvidas nas ações e interações estratégicas de atores estatais, blocos regionais, organizações multilaterais e governos subnacionais.

Considerando os desafios trazidos pela pandemia da COVID-19, o dossiê apresenta uma entrevista inédita com a Dra. Deisy Ventura, Professora Titular de Ética da Faculdade de Saúde Pública (FSP) da Universidade de São Paulo (USP). A entrevista aborda os achados da pesquisa "Mapeamento e Análise das Normas Jurídicas de Resposta à Covid-19 no Brasil" $(2021)^{1}$, relativos à intencionalidade das ações e omissões do governo federal brasileiro para a propagação da Covid-19 no Brasil. Destacam-se as discussões sobre os atores governamentais, seus interesses e suas decisões, e são ressaltadas a falta de coordenação na gestão da pandemia e a desconstrução de políticas públicas setoriais, sobretudo da política de saúde e da política externa, durante o governo Bolsonaro.

Os treze artigos do dossiê são organizados com base na afinidade temática em três seções: I) Crise política, relações federativas e a atuação internacional dos atores subnacionais, II) Cooperação internacional para o desenvolvimento e políticas públicas e III) Política externa brasileira e cooperação internacional: atores, interesses e alternativas.

${ }^{1}$ Disponível em: https://cepedisa.org.br/publicacoes/ 
A primeira seção é iniciada pelo o artigo "Conflitos entre governos subnacionais e o governo federal durante a pandemia de COVID-19: o estado de São Paulo e o caso da vacina CoronaVac", de Ana Tereza Lopes Marra de Sousa e Gilberto Rodrigues. Os autores examinam, especialmente, a atuação internacional do estado de São Paulo junto à Sinovac para a produção da vacina CoronaVac. O estudo elenca as explicações internacionais e domésticas para o conflito federativo entre a União e o governo do estado na matéria.

O artigo "Constâncias nos dissensos: o quadro normativo brasileiro e a emergência da 'paradiplomacia da resistência'", de Marinana Andrade e Barros, atualiza a discussão sobre o conceito e a prática da paradiplomacia no Brasil, no atual contexto de polarização e disputas políticas entre o governo federal e os governos estaduais, e apresenta o conceito de 'paradiplomacia da resistência'.

O artigo "O protagonismo do Mato Grosso do Sul para a resiliência do Corredor Rodoviário Bioceânico", escrito por Pedro Silva Barros e Julia de Souza Borba Gonçalves, explica as razões da resiliência da gestão desse projeto, criado em um momento de declínio da integração regional, com desintegração econômica-comercial, fragmentação política entre os países e crise das instituições de governança regional, especialmente na temática da infraestrutura. Os achados apontam que a resiliência da iniciativa é explicada pelo poder de atração da demanda da região Ásia Pacífico, notadamente a China, e pelo envolvimento ativo dos governos subnacionais em estabelecer a agenda junto aos governos centrais do Brasil, Paraguai, Argentina e Chile, com especial atenção à atuação do governo estadual de Mato Grosso do Sul, único estado brasileiro diretamente envolvido no projeto.

Finalizando a primeira seção, o artigo "Cooperação internacional em CT\&l: uma análise da cooperação entre as Fundações Estaduais de Amparo à Pesquisa e o Fundo Newton", de Barbara Vitória Marques Sá dos Santos, examina a cooperação internacional em CT\&I estabelecida entre o Conselho Nacional das Fundações Estaduais de Amparo à Pesquisa (CONFAP) e vinte e quatro de suas Fundações de Amparo à Pesquisa (FAP) com o Fundo Newton, iniciativa do governo britânico para promover o desenvolvimento social e econômico dos países parceiros por meio de pesquisa, ciência e tecnologia. Os resultados apontam para a importância de atores subnacionais para o apoio à cooperação internacional em CT\&l e para 
a complementaridade da atuação desenvolvida nos níveis subnacional e federal relativamente a esse assunto.

A segunda seção reúne os trabalhos que abordam o tema da "Cooperação internacional para o desenvolvimento e políticas públicas". O artigo que abre a seção, intitulado "Cooperação Internacional para o Desenvolvimento e Políticas Públicas: um campo de batalha pela autoridade do conceito de desenvolvimento internacional", escrito por Chyara Sales Pereira, discute a caracterização da cooperação internacional para o desenvolvimento como campo político das relações internacionais. A autora examina a disputa entre as organizações internacionais protagonistas desse campo - ONU e OCDE - em torno do conceito de desenvolvimento internacional, bem como das políticas públicas que são formuladas e implementadas a partir de sua definição.

Em uma linha similar, o artigo "A ONU e a difusão do desenvolvimento sustentável: o caso brasileiro", de Pascoal Carvalho Gonçalves e Bruno Domingos do Nascimento, identifica empiricamente o impacto do debate internacional na agenda governamental brasileira sobre o desenvolvimento. O trabalho aprofunda os estudos sobre a influência do ambiente internacional na formulação de políticas públicas domésticas, especificamente lançando luz no processo de formação da agenda governamental face à agenda internacional de desenvolvimento pactuada nos Objetivos de Desenvolvimento Sustentável (ODS).

Já o artigo "China e a Cooperação para o Desenvolvimento nos Financiamentos de Infraestrutura na América Central e Caribe", escrito por Ticiana Amaral Nunes e Thomaz da Costa Farias, analisa a expansão dos financiamentos em infraestrutura feitos pela China em países da América Central e Caribe, destacando as diferenças da atuação chinesa em relação à ideia tradicional de ajuda internacional ao desenvolvimento.

Por fim, no artigo intitulado "Na contramão do unilateralismo: assistência alimentar internacional dos Estados Unidos no governo Trump", Atos Dias e Thiago Lima abordam a assistência alimentar internacional dos Estados Unidos no Governo Trump e analisam a continuação da assistência alimentar internacional, que ocorre por influência de instituições nacionais e internacionais na política externa estadunidense, a despeito da resistência do presidente Trump. 
A terceira seção organiza as contribuições em torno do tema "Política externa brasileira e cooperação internacional: atores, interesses e alternativas". Assim, o artigo intitulado "Formação da agenda e a seleção das alternativas para a participação do Brasil na instalação da Sociedade Moçambicana de Medicamentos (SMM)", de Michelle Silva Santos e Andréa Freire de Lucena, analisa o processo de formação de agenda e seleção de alternativas que deu origem à participação do Brasil na instalação da SMM. O artigo destaca-se pela originalidade ao utilizar um modelo teórico majoritariamente aplicado para análise de políticas do âmbito doméstico (Modelo dos Fluxos Múltiplos) como ferramenta metodológica multivariada para analisar a formação da agenda e seleção de alternativas em ações de cooperação internacional.

O artigo "Instituições e organização da ajuda no processo de inclusão do ProSAVANA na agenda brasileira de cooperação internacional", de Laís Caroline Kuss, examina como fatores domésticos contribuíram para a adoção do ProSAVANA (uma modalidade triangular) na agenda da cooperação para o desenvolvimento (CID) do Brasil. Os achados apontam para a influência da Agência Brasileira de Cooperação $(A B C)$ e da Empresa Brasileira de Pesquisa Agropecuária (EMPRAPA) na CID agrícola do Brasil.

O artigo "A atuação do Brasil no âmbito da Cooperação Internacional para o Desenvolvimento: percepções sobre a 'Era Lula'", escrito por Tacilla Santos, revisita de forma crítica a atuação oficial brasileira no âmbito da cooperação internacional para o desenvolvimento, em especial na sua vertente Sul-Sul, durante os governos do presidente Lula.

Sobre as dinâmicas cooperativas no nível regional e a atuação brasileira, o artigo "A construção da cooperação sul-americana em segurança e defesa: o caso do Conselho de Defesa Sul-Americano", de Lisa Belmiro Câmara e Tomáz Espósito Neto, discute a construção Conselho de Defesa Sul-Americano (CDS), verificando se tal instituição pode ser entendida como parte do processo de concepção de uma identidade sul-americana, e se sua agenda e estrutura se adequam às necessidades da região.

Por fim, o artigo "Le Brésil dans les négociations sur la biodiversité au-delà des juridictions nationales", de autoria de Igor Magri de Queiroz, aborda a atuação do Brasil nas 
negociações para um acordo sobre a biodiversidade além das jurisdições nacionais, considerando a relevância global que o país tem na discussão sobre o desenvolvimento sustentável. Considerando o período analisado, chegou-se à conclusão de que o Brasil continua dedicando poucos recursos institucionais ao tema, sustentado a partir de uma ausência de diplomacia estratégica para o tema e uma concentração de recursos para questões oceânicas.

Para encerrar esta apresentação, algumas reflexões sobre as perspectivas e os desafios da cooperação internacional no contexto atual: sabe-se que países democráticos são mais propensos a cooperar do que países autocráticos (LEEDS, 1999). Sabe-se, também, que agrupamentos de países democráticos produzem acordos mais estáveis e mais críveis do que agrupamentos de países autocráticos ou mistos (LEEDS, 1999; LAS CASAS, 2016). A União Europeia e o bloco IBAS (Índia, Brasil, África do Sul) são evidências de experiências bemsucedidas de diferentes tipos de cooperação internacional entre países democráticos (LAS CASAS, 2016).

Não obstante, sabe-se, ainda, que a democracia enfrenta uma crise de grandes proporções no mundo contemporâneo, com a emergência de governos autocráticos por meio de procedimentos democráticos esvaziados de seus princípios constitutivos (LEVITZKY; ZIBLATT, 2018), como se observa hoje, por exemplo, no Brasil, na Polônia e na Hungria, ainda que haja controvérsias sobre seus determinantes e magnitude (PRZEWORSKI, 2020). Tal crise é alimentada por fenômenos como a pandemia em curso e as respostas egoístas que ela tem provocado, mesmo por parte de atores com sólida reputação mais cooperativa, como ocorre entre os países da União Europeia. Tais considerações sugerem, portanto, moderação e temperança nos prognósticos sobre as perspectivas da cooperação internacional e olhar atento para os seus desafios.

Finalmente, os organizadores deste dossiê agradecem todas as pessoas e instituições que contribuíram para a sua elaboração. Agradecimentos especiais são devidos à professora Deisy Ventura, pela entrevista, aos autores e pareceristas dos artigos, bem como à Revista Monções, pela oportunidade de sua publicação. Aos leitores, uma profícua e reflexiva leitura a partir das contribuições dos autores. 


\section{Referências}

AXELROD, Robert. A evolução da cooperação. São Paulo: Leopardo Editora, 2010.

AXELROD, Robert; KEOHANE, Robert O. Achieving cooperation under anarchy: strategies and institutions. World Politics, vol. 38, $n^{\circ} .1,1985$, pp 226-254.

CHATURVEDI, Sachin; SINGH, Kunal. Features of South-South Cooperation and global dynamics. Forum for Indian Development Cooperation, Policy Brief, n 1, 2014.

JAVED, Sumbal; CHATTU, Vijay K. Strengthening the COVID-19 pandemic response, global leadership, and international cooperation through global health diplomacy. Health Promotion Perspectives, vol.10, n. 4, 2020, pp. 300-305.

KEOHANE, Robert O. International Institutions: Two Approaches. International Studies Quarterly, Vol. 32, No. 4, 1988, pp. 379-396

LAS CASAS, Luciana. BRICS but no wall versus the IBSA cement: o problema da cooperação a partir de três níveis. 1. ed. Campina Grande: EDUEPB, 2016. 250p.

LEE, James, R. Climate Change and Armed Conflict: hot and cold wars. New York: Routledge, 2009.

LEEDS, Brett A. Domestic Political Institution, Credible Commitments and International Cooperation. American Journal of Political Science, vol. 43, n 4, 1999.

LEVITSKY, Steven; ZIBLATT, Daniel. Como as democracias morrem. Rio de Janeiro: Zahar, 2018 (Edição Kindle).

PRZEWORSKI, Adam. Crises da democracia. Rio de Janeiro: Zahar, 2020 (Edição Kindle).

RUZUM, Oliver; BOZORGMEHR, Kayvan. Global Health needs more than International Health Regulations - the case of Covid-19. Public Health Forum, vol. 28, n. 3, 2020 , p.p. 176-178.

SATRUSTEGUI, Koldo Unceta. Cooperación para el desarrollo: anatomía de una crisis. Revista de Ciencias Sociales, $n^{\circ} 47,2013$, p.p 15-29. 